\title{
Levantamento de Diretrizes de Interação Sonora para Aplicativos de Smartphones
}

\author{
Records on Sonic Interaction Guidelines for Smartphones Applications
}

QUARESMA, Manuela; Doutora em Design; LEUI | PUC-Rio

mquaresma@puc-rio.br

MOTTA, Isabela; Graduanda em Design; LEUI | PUC-Rio

isabela.canellas@gmail.com

ARAÚJO, Manuella; Graduanda em Design; LEUI | PUC-Rio

manuelladasaraujo@gmail.com

\section{Resumo}

Com o aumento do uso de smartphones, cresce também a quantidade de informações visuais e interações através de interfaces gráficas a serem apresentadas para os usuários. Assim, outras formas de interação passaram a ser exploradas para suprir essa demanda, como a interação por meio do som. Assim, este artigo buscou compilar as principais questões em torno do uso do som como canal informativo, por meio de um levantamento que contemplou princípios e diretrizes provenientes de publicações científicas e de grandes empresas de desenvolvimento de sistemas operacionais. Dessa forma, princípios e diretrizes sobre design de interação sonora foram reunidos, organizados e sintetizados em vinte e uma diretrizes sobre o assunto, organizadas em quatro categorias.

Palavras Chave: interação sonora; diretrizes de design; aplicativos de smartphone.

\begin{abstract}
With the increasing use of smartphones, the quantity of visual information and interactions to be presented to users through graphic interfaces also increase. Thus, other interaction forms started to be exploited to supply this demand. Therefore, this article aimed to compile the main issues around the use of sound as an informative channel, by means of a collecting that contemplated guidelines from scientific publications and from large operating systems development companies. Thus, principles and guidelines about sonic interaction design were assembled, organized and synthesized in twenty one guidelines about the subject, organized in four categories.
\end{abstract}

Keywords: sonic interaction; design guidelines; smartphone applications. 


\section{Introdução}

O uso de smartphones no Brasil é crescente, sendo um meio cada vez mais popular e com mais funcionalidades para os usuários. Segundo o Google Consumer Barometer (GOOGLE, 2017a), a porcentagem de brasileiros que usam um smartphone subiu de 14\%, em 2012, para 67\% em 2017. Contudo, o uso deste tipo de aparelho não se limita apenas às ligações telefônicas, sendo usado para desempenhar diversas tarefas. Ainda segundo a mesma publicação (GOOGLE, 2017a), 60\% dos brasileiros fazem uso mais frequente do smartphone do que de computadores ou tablets.

Com o grande número de atividades que podem ser realizadas em smartphones, surge também a necessidade de apresentar ao usuário informações de diversas naturezas e hierarquias, como feedbacks, instruções, comandos etc. Apresentar todas essas informações de maneira eficaz pode ser um desafio para designers de interação, principalmente em smartphones, nos quais diferentes aplicativos funcionam paralelamente e os usuários realizam várias ações ao mesmo tempo. No entanto, o uso de diferentes canais de interação pode ser uma potente alternativa para enfrentar esse desafio.

O canal mais comum para apresentação de informações é o visual, no entanto, essa modalidade apresenta algumas desvantagens, como a necessidade de visualizar a interface o tempo todo. Assim, a apresentação de mensagens pelo canal auditivo pode ser uma alternativa e um complemento à visão. Segundo Saffer (2013), o áudio pode trazer vantagens em situações que o usuário não pode olhar para a tela, como quando está dirigindo, ou em momentos que uma ação está acontecendo em segundo plano e o usuário não está prestando atenção. Ainda, o som chega ao cérebro mais rapidamente do que informação visual (SAFFER, 2013).

\section{Interação sonora}

É possível perceber o uso do som como canal informativo em diversas mídias, como os feedbacks sonoros gerados por computadores, micro-ondas, alarmes, jogos etc. 0 design de interação sonora (Sonic Interaction Design, ou SID) "usa o som para comunicar uma informação, um significado, uma estética ou emoção em contextos interativos. (...) Seu desafio é criar interações adaptáveis que respondam constantemente aos gestos de um ou mais usuários" (SERAFIN et al., 2011, tradução nossa). Assim sendo, existem diversos tipos de interação sonora que são empregados em aplicativos para smartphones de diferentes maneiras, desde notificações em aplicativos de mensagens até comandos de voz para GPS's.

Dada a multiplicidade de interações em smartphones, a disponibilidade de uma ampla gama de sons e a possibilidade de manipular suas características para alterá-los, o som e a interação sonora são uma ferramenta poderosa de interação, principalmente porque seres humanos têm uma boa capacidade de perceber padrões em sons (KORTUM, 2008). No entanto, mesmo dentro desse canal informativo, ainda existe a necessidade de entender e variar o tipo de interação sonora adequado a cada interação com a interface. Por exemplo, uma ação do sistema, como dar as direções de uma rota no Waze, requer uma carga de informação muito mais complexa e específica do que a notificação de uma mensagem em um aplicativo de mensagens ou e-mail. Para diferentes necessidades existem, então, alguns tipos diferentes de interação sonora, como comandos de voz e sons simples abstratos.

Considerando a existência de diferentes tipos de interação sonora e sua aplicação perceptível no dia a dia, é esperado que exista um amplo número de recomendações sobre o uso 
da interação sonora. No entanto, justamente por existir uma grande variedade de orientações sobre o assunto, fornecidas tanto pela literatura, quanto por diretrizes de desenvolvimento de grandes empresas de softwares, existe, também, uma certa dispersão dessa informação.

\section{Metodologia}

Este estudo teve como objetivo reunir, organizar e sintetizar princípios e diretrizes de interação sonora para o desenvolvimento de interfaces sonoras para aplicativos. Para isso, foram conduzidas as seguintes etapas:

1. Levantamento de princípios e diretrizes para o desenvolvimento de interfaces sonoras para aplicativos, a partir de guias de desenvolvimento de design de interface do usuário oferecidos pelos principais sistemas operacionais do mercado (Apple, 2017; Google, 2017);

2. Revisão bibliográfica de publicações a respeito de usabilidade e interação humanocomputador em interfaces, no que se referia a interação sonora (CLARK, 2010; HOOBER; BERKMAN, 2011; KORTUM, 2008; SAFFER, 2013) também com o intuito de buscar por princípios e diretrizes de design de interfaces sonoras;

3. Análise e organização das principais diretrizes em um Diagrama de Afinidades (BARNUM, 2011), utilizando uma abordagem híbrida entre bottom-up, para as diretrizes gerais, e top-down, para as que já se encontravam originalmente categorizadas, e;

4. Definição de novas diretrizes que sintetizam o material reunido previamente, divididas nas categorias identificadas na etapa anterior;

Assim, a seção de resultados deste artigo apresenta vinte e uma diretrizes divididas nas categorias: Estrutura dos sons no sistema; Alertas; Ícones sonoros e ícones auditivos; e Interação por voz, resultado da síntese do material coletado sobre interação sonora em interfaces para aplicativos.

\section{Resultados}

Como já mencionado, o som possui características vantajosas que o tornam uma boa ferramenta para o design de interação. No entanto, assim como na modalidade visual, o canal auditivo pode apresentar algumas desvantagens que exigem cuidados no seu uso. Segundo Kortum (2008), o nível de urgência apresentado por um som deve estar relacionado com o nível de urgência da mensagem que está sendo transmitida. Ainda, o uso exagerado do canal auditivo pode resultar na perda do significado da mensagem, sendo interpretada pelos usuários apenas como barulho (KORTUM, 2008) e, eventualmente, no desligamento do feedback sonoro (GINSBURG, 2010). Assim,

Diretriz 1: 0 aplicativo sempre deve fornecer para o usuário a opção do desligamento do feedback sonoro, pois os sons podem ser intrusivos, repetitivos e irritantes.

\subsection{Estrutura dos sons no sistema}

Dentro de um sistema de informações sonoras, é possível ter diversos tipos de mensagens com funções e objetivos distintos. Por exemplo: uma notificação sonora de mensagem, como a do Whatsapp, tem a função de mostrar ao usuário que ele recebeu uma mensagem de texto, que ficará arquivada no aplicativo mesmo depois de ser lida. Em contraste, o toque do celular tem como função alertar sobre o recebimento de uma ligação telefônica, ação que requer uma resposta imediata (atender à chamada), e que, sem resposta, gera uma situação irreversível para o usuário 
(a perda da chamada). É possível perceber que, além de possuírem significados distintos, mensagens carregam hierarquias diferentes quando se trata de urgência. Por isso, é necessário entender as prioridades dos usuários, tarefas e necessidades para criar uma estrutura hierárquica coerente para a apresentação de mensagens sonoras.

Sobre esse tópico, as diretrizes de User Interaction da Apple (APPLE, 2017a) sugerem que o uso de diferentes categorias para o áudio pode ser útil em sistemas que contam com diversos áudios, ajudando na mixagem, na reprodução paralela e no silenciamento de determinados sons. Ainda segundo a Apple (2017b), os critérios para criação dessas categorias devem considerar o "ambiente sonoro" do sistema, isto é, o que está sendo reproduzido por outros aplicativos, e o significado das mensagens, de forma a corresponder às expectativas dos usuários sobre o que está sendo informado.

Em aplicativos de jogos, por exemplo, é possível perceber a aplicação de categorias distintas de áudio e como sua existência facilita a interação do aplicativo com o usuário e com outros aplicativos. Em jogos, geralmente, os sons se apresentam em duas categorias com significados diferentes: A trilha sonora, que é a ambientação sonora do jogo e, por isso, cria a expectativa por parte do usuário de que a música tocará como plano de fundo; E o efeitos sonoros, que servem como feedback para as ações do jogador, criando uma expectativa de causalidade com as ações dentro do jogo. É possível observar que a maioria dos jogos oferece a opção de desligamento dos sons separadamente, dando liberdade ao jogador para escolher o que quer ouvir. Assim, se o "ambiente sonoro" do aparelho estiver ocupado com a reprodução de músicas de outro aplicativo, ou, até mesmo, uma ligação telefônica, é possível desligar apenas a trilha ou os efeitos sonoros, permitindo ações paralelas do usuário no sistema. Dessa forma, é recomendado:

\section{Diretriz 2: Categorias de áudio devem ser criadas para facilitar a interação do aplicativo com sons do sistema operacional e outros aplicativos.}

Uma vez estabelecida a necessidade da criação de categorias de som para os áudios de um aplicativo, é importante entender a diferença de hierarquia que as mensagens carregam, julgando as prioridades do usuário. A reprodução de áudio, seja por meio de mídias como músicas e vídeos, por chamadas telefônicas ou até a rota de um GPS, também deve ter uma hierarquia. É necessário entender quais reproduções podem ou devem ser interrompidas por outras, e quais não.

Segundo as diretrizes de interação da Apple (APPLE, 2017a), um aplicativo deve informar aos outros aplicativos quando começar e quando terminar de tocar um áudio temporário que precise interromper uma reprodução paralela. Por exemplo, se um usuário está utilizando o Facebook e reproduzindo uma música no Spotify, em segundo plano, e então começa a reproduzir um vídeo no Facebook, o Spotify pausa a reprodução da música enquanto o vídeo estiver sendo reproduzido, e, ao fim do vídeo, retoma a música de onde o usuário parou. Isso acontece, justamente, porque os aplicativos informam ao sistema sobre o status da reprodução de mídia.

Alguns cuidados devem ser tomados na interrupção e retomada da reprodução de áudio. Segundo a Apple (2017a), áudios interrompidos temporariamente podem ser retomados, como uma música interrompida por uma ligação telefônica. Já interrupções permanentes, como o início da reprodução de uma playlist, não podem ser retomados automaticamente. Além disso, é importante retomar uma reprodução interrompida do ponto em que o áudio foi pausado, de forma que o usuário possa voltar de onde parou (APPLE, 2017a). Assim: 
Diretriz 3: 0 aplicativo deve considerar o tipo de interrupção externa e a função da sua reprodução antes de decidir continuá-la automaticamente quando for interrompido.

Diretriz 4: Quando a execução de uma mídia de áudio ou vídeo for pausada, o aplicativo só deve continuar a reprodução a partir do ponto que foi cessada.

\subsection{Alertas}

Uma das grandes vantagens do som é sua capacidade de atrair a atenção mesmo quando o usuário não está atento e olhando para a fonte de informação. A interação sonora explora as habilidades humanas de monitorar e processar diversos áudios paralelamente (FITCH \& KRAMER, 1994 apud WALKER; NEES, 2011) e de detectar áudio rapidamente (KRAMER et al., 1999; MOORE, 1997 apud WALKER; NEES, 2011). Por essas características, o feedback sonoro é ideal para alertas e alarmes. Em uma situação na qual olhar para a tela do smartphone pode ser perigoso, como durante a condução de um veículo, o recebimento de alertas sonoros sobre a presença de um radar de velocidade, por exemplo, dispensa a necessidade do motorista de desviar seu olhar da via para o aparelho, diminuindo a distração da interação.

É importante ressaltar, no entanto, que um dos princípios para feedbacks, de forma geral, é não sobrecarregar os usuários com feedbacks (SAFFER, 2013). Essa recomendação também se aplica para feedbacks sonoros em alertas, para que não se tornem irritantes, inconvenientes ou repetitivos. De acordo com a Apple (2017c), alarmes e alertas devem ser usados apenas em situações importantes, dessa forma, quando acionados, serão levados a sério pelos usuários. Além disso, alertas devem ser distintos e únicos e nunca devem interromper comunicações de voz (HOOBER; BERKMAN, 2011). Ainda, Hoober (2011) recomenda que a repetição de um alerta para uma mesma ação só deve ocorrer se essa ação demandar uma resposta ativa do usuário, como um despertador. Já para ações de baixa prioridade, como e-mails ou mensagens, o autor sugere que os alertas sejam agrupados, uma vez que o sistema só precisa chamar a atenção do usuário para tela do dispositivo uma única vez (HOOBER; BERKMAN, 2011).

É possível perceber a importância da aplicação dessas recomendações em um cenário prático. Por exemplo, se um usuário estiver tendo uma conversa em grupo no WhatsApp, um alerta sonoro permite que ele realize outras tarefas enquanto aguarda uma resposta, sem que tenha que ocupar seu canal visual com o monitoramento do aplicativo. No entanto, se o usuário começar a receber muitas mensagens seguidas desse grupo, o uso de um alerta sonoro para cada uma dessas mensagens seria intrusivo e irritante, sobrecarregando o usuário. Assim:

Diretriz 5: 0 aplicativo deve usar sons em alertas para situações em que o canal visual do usuário está ocupado.

Diretriz 6: A repetição de alertas em aplicativos deve ser utilizada com cautela. Ações de baixa urgência e de mesma natureza iniciadas ao mesmo tempo podem ser agrupadas em um único som.

Nas seções anteriores, algumas diretrizes de natureza estrutural foram colocadas. No entanto, estar ciente apenas de como usar o canal auditivo não é suficiente. É necessário, também, saber quais tipos de interação sonora utilizar em cada situação. Por isso, serão apresentadas, nas próximas seções, os tipos existentes de interação sonora e diretrizes sobre como e onde utilizá-las. 


\section{3 Ícones Sonoros e Ícones Auditivos}

\subsection{1 Ícones Sonoros}

Os Ícones sonoros (earcons), muito comuns em smartphones, são "mensagens de áudio nãoverbais usadas em interfaces humano-computador para apresentar informação sobre um objeto computacional, uma operação ou uma interação" (BLATTNER; SUMIKAWA; GREENBERG, 1989, p. 13, tradução nossa). É possível perceber seu uso para notificações em aplicativos de mensagem como Whatsapp, em diversos tipos de feedbacks do sistema, como o som do teclado e o som de bloqueio de tela do iOS, ou, como já comentado anteriormente, em efeitos sonoros de jogos, como ferramentas de feedback e imersão.

Uma das grandes vantagens dos ícones sonoros é a velocidade com a qual as mensagens são apresentadas e interpretadas quando comparados a outros tipos de interação, como os comandos de voz. Uma mensagem que levaria alguns segundos para ser enunciada por uma interface de voz só levaria frações de segundos para ser apresentada por um ícone sonoro (SAFFER, 2013). No entanto, por serem sons abstratos e simbólicos, os ícones sonoros precisam ser aprendidos pelos usuários, e, por isso, devem ser simples de serem compreendidos e aprendidos (ROGINSKA, 2013). Ainda, segundo Saffer (2013), deve-se evitar usar ícones sonoros iguais ou parecidos para ações distintas, caso contrário, seu significado pode ser mal interpretado. Assim: ação.

Diretriz 7: 0 aplicativo deve usar Ícones sonoros simples e que sejam únicos para cada

Diretriz 8: 0 aplicativo deve usar ícones sonoros para situações nas quais a mensagem a ser apresentada tenha significado simples e precise ser exposta de forma rápida ao usuário.

Diferente da interação por voz, que conta com o alto grau de especificidade da fala, os ícones sonoros costumam trazer mensagens com significados simples, porque a quantidade de informação que conseguem apresentar é limitada (SAFFER, 2013). No entanto, pela natureza física das ondas sonoras, é possível manipular suas características para aumentar a quantidade de ícones sonoros a serem utilizados, assim como seus significados (ROGINSKA, 2013; SAFFER, 2013). O timbre é a assinatura única de cada som. Já a frequência de uma onda sonora determina se o som será mais grave (baixa frequência) ou mais agudo (alta frequência), o volume varia entre sons mais altos e mais baixos, e o intervalo de silêncio entre dois pulsos pode ser variado para criar ritmos mais lentos (intervalo maior) ou mais rápidos (intervalo menor).

Segundo Roginska (2013), pessoas são sensíveis a intervalos de frequência, isto é, conseguem identificar, comparativamente, se um som é mais grave ou mais agudo do que outro tocado em sequência. Em contraste, o volume é o parâmetro sonoro cujas alterações são as menos percetíveis para o ouvido humano, sendo o menos útil para a interação sonora (BUXTON, GAVER \& BLY, 1991 apud. ROGINSKA, 2013). Por fim, a autora aponta que o ritmo é a característica mais proeminente para os usuários em ícones sonoros (ROGINSKA, 2013).

A possibilidade de manipulação dessas características do som é essencial para a interação sonora, uma vez que é possível fazer uma correspondência entre o som resultante e o significado de uma mensagem. Segundo Saffer (2013), ícones sonoros devem ser compatíveis com o teor emocional da mensagem que está sendo apresentada. É possível perceber a eficácia disso em alertas de colisão de sensores de ré, por exemplo. O sensor de ré usa ícones sonoros com diferentes intervalos de silêncio entre os pulsos (variação de ritmo) para apresentar informações sobre a 
distância do carro até um determinado objeto atrás dele. Quanto mais próximo do objeto, e, portanto, mais urgente é o teor da mensagem, mais rápido é o ritmo.

Apesar de os ícones sonoros serem eficientes para a apresentação de mensagens, um cuidado deve ser tomado na manipulação de suas características para que não se tornem irritantes e intrusivos. Segundo Saffer (2013), os melhores ícones sonoros são curtos, com menos de um segundo de duração. Ainda, é necessário evitar ícones sonoros muito estridentes ou muito suaves, para que não sejam intrusivos demais ou passem despercebidos pelos usuários (SAFFER, 2013).

Pelo o exposto acima, ao projetar ícones sonoros, deve-se considerar que:

Diretriz 9: As características mais proeminentes do som são a frequência e o ritmo, e devem ser manipuladas para uma melhor diferenciação entre as mensagens.

Diretriz 10: A informação que a mensagem precisa apresentar deve ser considerada para o design de um ícone sonoro, de forma que sempre passe o significado da mensagem (urgência, função, nível de especificidade).

Diretriz 11: 0 aplicativo deve evitar ícones sonoros intrusivos demais ou muito suaves.

\subsection{2 Ícones Auditivos}

Similares aos ícones sonoros, Buxton, Gaver e Bly (1994) definem os ícones auditivos como:

“[...] sons do dia a dia projetados para apresentar informações sobre ações por meio de analogias com eventos que emitem som no dia a dia [...]. Eles (ícones auditivos) usam uma estratégia similar a usada na criação de ícones visuais, mapeando eventos em sistemas computacionais e se relacionado a ações do dia a dia para auxiliar no aprendizado e na compreensão". (BUXTON; GAVER; BLY, 1994, p. 1, tradução nossa).

Ao contrário dos ícones sonoros, de natureza abstrata, os ícones auditivos estão diretamente relacionados com ações do mundo real, e por isso, é esperado que seu significado seja intuitivo (ROGINSKA, 2013). Exemplos de ícones auditivos podem ser encontrados no aplicativo de e-mail do iOS, que usa o som de um objeto sendo arremessado para representar um e-mail sendo enviado. É possível, também, criar famílias de ícones auditivos usando o mesmo tipo de som para representar objetos ou ações computacionais similares (ROGINSKA, 2013). Por exemplo, o Mac OS usa uma família de dois ícones auditivos para sonorizar sua lixeira. O primeiro é o som de um papel amassado sendo jogado em uma lata de lixo quando um arquivo é deletado, e o segundo é o som dessa lata de lixo sendo esvaziada, para representar o esvaziamento da lixeira.

Ícones auditivos possuem características vantajosas para a interação sonora. Segundo Rogisnka (2013), por usarem sons do dia a dia, os ícones auditivos são fáceis de serem lembrados e aprendidos e tornam a interface mais agradável. Ainda, os ícones auditivos podem ser rapidamente associados com seu equivalente visual na interface, uma vez que ambos trabalham com analogias (ROGINSKA, 2013). No entanto, um dos grandes problemas dos ícones auditivos acontece em função de sua própria natureza associativa, uma vez que nem todas as ações computacionais têm um equivalente no mundo real (ROGINSKA, 2013). Dessa forma:

Diretriz 12: Aplicativos devem usar ícones auditivos, isoladamente ou em família, para representar ações computacionais por meio de analogias com ações do mundo real, quando possível.

É notável que ícones sonoros e auditivos trazem diversas vantagens para interfaces sonoras, 
mas as lacunas que deixam tornam necessária a existência de outros tipos de interação por meio do som.

\subsection{Interação por Voz}

A interação sonora por comandos de voz acontece quando é realizado um comando pelo usuário para o sistema (entrada de voz) ou quando o sistema fornece uma orientação ou uma resposta à uma ação do usuário ou dele mesmo (saída de voz), sendo essa interação de forma oral e verbal. Muito comuns em sistemas GPS e em recentes assistentes pessoais, como a Siri e o Google Assistant, os comandos de voz podem ser apresentados de forma totalmente auditiva ou em conjunto com um aparato visual.

A interação por voz oferece vantagens como ferramenta de interação. Segundo Roginska (2013), os comandos de voz têm um grande nível de especificidade na apresentação da mensagem e não demandam que o usuário aprenda como usá-los, uma vez que o ser humano usa a fala constantemente em seu dia a dia. No entanto, os comandos de voz também apresentam desvantagens. Por expressarem mensagens complexas, os comandos de voz são lentos e podem atrapalhar ou distrair o usuário se ele estiver envolvido em uma tarefa de voz ou verbal, como a sobreposição do som de um GPS em uma conversa entre motorista e passageiro no carro, ou de uma resposta da Siri enquanto o usuário está escrevendo um e-mail. Além disso, para processos contínuos a saída de voz pode ser intrusiva (ROGINSKA, 2013).

\subsubsection{Entrada de Voz}

De forma geral, as interfaces que se baseiam na interação por comandos de voz requerem a entrada de um comando do usuário. Esse tipo de interação gera, de certa forma, um diálogo entre o humano e a máquina. Assim, para que essa "conversação" aconteça de forma eficiente, é preciso que a interface considere diversos fatores que são naturais ao usuário, uma vez que a comunicação verbal e oral é própria ao humano.

Para que haja o mínimo de conversação, é preciso estabelecer uma linguagem a partir da qual a comunicação irá acontecer, além de manter uma coerência entre a expectativa gerada por essa linguagem no usuário e o que será, de fato, executado pelo sistema. Segundo a Apple (2017d), é importante criar frases com exemplos para ensinar ao usuário quais ações a Siri pode executar, sendo possível, também, criar um vocabulário customizado para o aplicativo, por meio de termos únicos e não genéricos que podem ser ensinados à Siri. Ainda, a empresa recomenda que o aplicativo corresponda às expectativas do usuário executando seus comandos e o levando direto ao conteúdo requisitado, sem passar por telas de transição desnecessárias (APPLE, 2017e). Assim:

Diretriz 13: 0 aplicativo deve reconhecer a linguagem do usuário e, quando for preciso, deve mostrar quais ações consegue executar, sejam elas genéricas ou próprias ao aplicativo.

Outro aspecto importante a ser considerado são os erros. Apesar de uma linguagem ser estabelecida para a interação por voz, é importante lembrar que a lógica e precisão por parte dos usuários podem ser diferentes do esperado, uma vez que a linguagem natural utilizada por eles, muitas vezes, não atende a padrões lógicos computacionais (GOOGLE, 2017b). Além disso, fatores técnicos como a falha no reconhecimento de comandos ou a falha da captação do input do usuário podem gerar problemas para a interação por voz. É necessário, então, buscar estratégias para minimizar o espaço deixado para erros.

De acordo com o documento Actions on Google (GOOGLE, 2017b), nem tudo que é 
considerado um "erro" como comando de voz está necessariamente errado, já que existem diversas maneiras de frasear um comando. Os "erros" são, justamente, o oposto de falhas, sendo oportunidades de aprendizado para a interface adquirir nova informação sobre como o usuário criaria seus comandos naturalmente. Entendendo como frases podem ser construídas e prevendo como o vocabulário pode ser estruturado pelo usuário, é possível antecipar que tipo de "erros" humanos podem acontecer (GOOGLE, 2017b). Por exemplo, se um usuário precisa fazer uma ligação, ele pode pedir à Google Assistant: "Quero fazer uma ligação para João", e a Siri irá fazer a ligação. No entanto, uma outra forma de estruturar o comando, que resultaria na mesma resposta do sistema, poderia ser: "Quero falar com João". Essa frase funciona porque há uma flexibilidade no reconhecimento desses comandos pela Siri, que não trata a ausência da palavra "ligação" como um erro, mas é capaz de associar a palavra "falar" ao ato de fazer uma ligação, executando o comando.

Mesmo com diversas diretrizes sobre interação por voz, ainda existem algumas barreiras colocadas pelas limitações na tecnologia, tanto na captação da voz quanto no reconhecimento do comando em si. Assim, algumas dessas barreiras geram reflexos negativos na interação por voz entre o usuário e a interface. Pela natureza inflexível da maioria das interfaces de voz do mercado, os usuários já estão acostumados a dar respostas literais e não naturais. Sobre esse tópico, a Google (2017b) sugere que a interface evite tentar ensinar ao usuário como falar e que não formule as respostas para os "erros" com um tom negativo. Dessa forma, considerando o exposto acima:

\section{Diretriz 14: 0 aplicativo deve evitar o uso de comandos prontos e inflexíveis e deve considerar como um comando pode ser colocado de forma a prever possíveis reformulações por parte do usuário.}

\subsubsection{Respostas do sistema}

As respostas do sistema, em termos de saída de voz, são os feedbacks, instruções, soluções e recuperações que uma interface de voz pode dar quando recebe um comando ou ação do usuário. Como já discutido na seção anterior, os comandos de voz se assemelham muito a um diálogo entre humano e máquina, e, por isso, é importante elaborar com cautela quais tipos de respostas serão dados pela interface nessa "conversa".

Para que uma conversação entre usuário e interface siga um fluxo natural é preciso comunicar que a interface está acompanhando os pedidos do usuário e está pronta para continuar a interação (GOOGLE, 2017c). Para isso, a Google (2017d) sugere o uso dos reconhecimentos: “(...) palavras ou frases como Ok, Claro, Obrigado e Entendi, que asseguram as pessoas que elas foram ouvidas e trazem fluidez e naturalidade ao diálogo" (GOOGLE, 2017d, tradução nossa). Os reconhecimentos devem ser usados para comunicar informações como correções ou confirmações, mas devem ser usados com cautela para evitar repetições (GOOGLE, 2017d).

Ainda, por sua natureza lenta, interfaces de voz podem demandar tempo na interação, por isso, as respostas para o usuário devem ser eficientes e rápidas, de forma a reduzir a necessidade de mais comandos (APPLE, 2017e). É recomendado que, ao apresentar uma resposta, a ação principal deve ficar no fim da frase (SAFFER, 2013), assim como informações novas ao usuário, seguindo o princípio de colocar o foco do comando no final (GOOGLE, 2017e). Ainda, segundo a Apple (2017f), deve-se minimizar ao máximo o tempo de execução dos comandos. Por fim, é necessário observar como as respostas serão formuladas para que a interface de voz nunca seja ofensiva ou humilhante (APPLE, 2017e). Assim: 
Diretriz 15: As respostas de voz de um aplicativo devem ser apresentadas de forma rápida, clara, com o mínimo de comandos possível e nunca deve utilizar linguagem imprópria.

Diretriz 16: 0 aplicativo deve usar palavras curtas para sinalizar ao usuário que está engajado na conversa, mas não deve torná-las repetitivas.

Diretriz 17: $O$ aplicativo deve falar frases curtas e que as ações ou novas informações sejam sempre dadas no final da frase.

Como exposto anteriormente, problemas técnicos de captação de voz e a linguagem utilizada pelo usuário podem resultar em erros de reconhecimento ou interpretação de uma mensagem de voz. Por isso, mesmo com os cuidados preveni-los, é importante desenvolver estratégias para dar suporte ao usuário em caso de falha.

Eventualmente, alguns usuários podem ficar confusos quanto ao que foi apresentado pela interface ou ao que devem dizer. O documento Actions on Google (GOOGLE, 2017c) sugere que a interface esteja preparada para repetir uma resposta ou receber pedidos de ajuda. A empresa também recomenda que a interface lembre os usuários confusos do caminho que percorreram ou o quanto falta para terminarem o comando, de forma a colocar os usuários de volta na interação. Por fim, é importante que a interface ofereça a possibilidade de interrupção de uma tarefa pelo usuário, e, posteriormente, forneça informações sobre como retomá-la do ponto de interrupção (GOOGLE, 2017c). Dessa forma:

Diretriz 18: A interface deve estar preparada para lidar com usuários confusos. Uma maneira eficiente para tal é relembrá-los do ponto em que se encontram na interação e permitir que a resposta possa ser repetida.

Diretriz 19: 0 aplicativo deve permitir que os usuários abandonem uma interação incompleta, além de facilitar sua retomada do ponto de interrupção.

Quando projetar respostas para a interface de voz, é necessário estar ciente da necessidade de estratégias de confirmação. Esse tipo de resposta é importante para deixar os usuários mais confiantes em relação a o que a interface está captando e interpretando sobre suas demandas, caso contrário, o comando pode ser erroneamente interpretado, levando o sistema a executar uma ação diferente da requisitada (GOOGLE, 2017e). Dessa forma:

\section{Diretriz 20: 0 aplicativo deve comunicar ao usuário o que foi entendido de seu comando.}

Entretanto, alguns cuidados devem ser tomados com as confirmações. Segundo a Google: "A confirmação é como a interface de voz certifica às pessoas que uma pergunta, comando ou resposta foi entendido corretamente" (GOOGLE, 2017d, tradução nossa). Pela natureza lenta dos comandos de voz, confirmações em excesso podem tomar muito tempo dos usuários. Porém, dependendo das consequências que um erro na execução de um comando específico pode trazer ao usuário, não utilizar uma confirmação pode ser arriscado. A Google (2017d) sugere o uso de estratégias de confirmação explícita para ações difíceis ou impossíveis de serem revertidas, e de confirmação implícita para ações de baixo risco e em que o sistema tenha confiança no reconhecimento do comando.

Por exemplo, um usuário pode pedir à Siri que faça uma ligação: "Quero fazer uma ligação para João". Assim, se o sistema tiver confiança sobre o reconhecimento do comando - a captação foi feita sem erros e o "João" referido é o único "João" na lista de contatos - a Siri irá fazer a ligação, 
dando como resposta "Ligando para João". Esse é um exemplo de resposta implícita, uma vez que a Siri não pergunta diretamente ao usuário antes de realizar a ação ("Você quer ligar para João?"), apenas fala o nome do contato para quem está ligando, confirmando o reconhecimento do comando. Esse tipo de confirmação é possível pela natureza de baixo risco da ação, já que o usuário pode interromper a chamada em caso de erro. Porém, ao receber um pedido de enviar uma mensagem como: "Me atrasarei, estou no trânsito", a Siri irá ler a mensagem para o usuário antes de enviá-la, confirmando explicitamente o que foi reconhecido antes de enviar. Essa estratégia explicita é usada nesse caso porque a confiança no que foi reconhecido não é alta e a ação de enviar uma mensagem com conteúdo errado é irreversível. Assim:

Diretriz 21: Ao projetar estratégias de confirmação em respostas por voz do aplicativo deve-se ponderar quando usar uma confirmação implícita ou explícita na execução de um comando, considerando as prioridades do usuário e o contexto da ação.

Apesar dos tipos de interação sonora terem desvantagens quando observados isoladamente, suas características distintas acabam compensando umas as outras quando usados em conjunto. Por exemplo, o aplicativo do Waze faz uso de comandos de voz para apresentar informações específicas como direções, nomes de ruas ou distâncias, mensagens que seriam impossíveis de serem apresentadas por ícones sonoros ou ícones auditivos. No entanto, para avisar sobre a presença de um radar de velocidade, o Waze usa um ícone sonoro como alerta, apresentando a informação de forma rápida para que o motorista possa reduzir a velocidade a tempo. Assim, é possível perceber que junção dos tipos de interação sonora faz com que a apresentação das mensagens seja eficiente e precisa.

\section{Considerações Finais}

Este artigo apresentou um estudo que teve como objetivo reunir, organizar e sintetizar princípios e diretrizes de design sobre a interação sonora. Para isso, foi feito um levantamento das diretrizes de interação das principais empresas de desenvolvimento de software do mercado, assim como uma revisão bibliográfica sobre design de interação e de interfaces sonoras. Assim, vinte e uma diretrizes foram elaboradas e organizadas em quatro categorias na seção de resultados deste artigo. Foi possível perceber, ao longo dos resultados deste estudo, que a interação sonora é fundamental para a elaboração de uma interação completa, compensando algumas desvantagens do canal visual e possibilitando interações que só o áudio pode trazer.

Em primeiro lugar, o som é ideal para situações nas quais os olhos do usuário estão ocupados, como na condução de veículos, monitoramento de informações em paralelo ou quando o usuário simplesmente não está próximo da fonte de informação visual. Além do som atrair rapidamente a atenção dos usuários, sendo eficaz para alertas e situações de alta urgência, as pessoas também são sensíveis a mudanças em parâmetros de sons, o que torna possível a variação de significados das mensagens sonoras. A interação sonora conta, ainda, com um recurso muito intuitivo para seres humanos, a comunicação por voz. Muito útil em cenários nos quais a informação a ser apresentada é muito complexa ou o dispositivo que emite a mensagem não tem uma interface visual, a interface de voz complementa os sons abstratos, compensando algumas de suas desvantagens, e vice-versa.

Como foi possível observar no decorrer dos resultados deste artigo, ainda existem desvantagens no uso do som. Se mal projetadas, interfaces sonoras podem ser intrusivas, irritantes ou inconvenientes, podendo levar o usuário a desligar o feedback sonoro e podendo ser perigoso 
em situações em que a distração pode trazer riscos para o usuário, como na condução de um veículo. No entanto, existem diversas recomendações disponíveis, cuja eficácia é legitimada por grandes empresas do mercado de software e pela ampla literatura, que possibilitam o design de interação sonora responsável e efetivo. Ainda, há a possibilidade de mesclar os diferentes tipos de interação sonora e concilia-los com outros canais informativos, como o visual e o tátil, para compensar problemas específicos de cada um deles.

O uso do canal auditivo para apresentação de informação ainda precisa ser explorado, mas provavelmente irá aparecer cada vez mais no futuro. Já é possível identificar o uso desse canal em produtos como assistentes pessoais e os produtos decorrentes da Internet das Coisas. A Amazon Echo, por exemplo, conta apenas representações visuais em seus botões físicos, e todo o feedback digital é feito por meio do som, com sua assistente Alexa. Outro exemplo proeminente são os robôs, que contam cada vez menos com interfaces visuais, baseando suas interações em gestos e som.

No âmbito de cenários futuros, como, por exemplo, carros autônomos a possibilidade do usuário se distrair enquanto o carro dirige é quase inevitável, já que a tendência é o aumento da confiabilidade dos motoristas no sistema. $\mathrm{O}$ uso de interfaces sonoras, por sua capacidade de chamar atenção mais rapidamente, possibilita que o usuário possa realizar outras ações sem ter que monitorar uma interface visual para detecção de problemas. Com o crescimento de produtos com interfaces visuais pequenas ou inexistentes, tipos alternativos de interface como a sonora e a tátil poderão ser fundamentais para a interação dos usuários com esses produtos.

Ainda existe uma preocupação muito grande com as interfaces visuais, o que se justifica pela disponibilidade praticamente inesgotável desse tipo de interação em produtos físicos e virtuais. No entanto, com os avanços da tecnologia e das formas de interação, é necessário pensar na interação do usuário com o produto em todos os seus aspectos e formas, sejam eles visuais, auditivos, táteis ou gestuais.

\section{Referências}

APPLE. User Interaction - Audio - iOS Human Interface Guidelines. Disponível em: $<$ https://developer.apple.com/ios/human-interface-guidelines/user-interaction/audio/>. Acesso em: 23 ago. 2017a.

APPLE. Apple Human Interface Guidelines. Disponível em: <https://developer.apple.com/design/>. Acesso em: 23 ago. 2017b.

APPLE. Alerts - System Elements - Human Interface Guidelines for CarPlay Apps. Disponível em: $<$ https://developer.apple.com/carplay/human-interface-guidelines/system-elements/alerts/>.

APPLE. HomeKit - Technologies - iOS Human Interface Guidelines. Disponível em: <https://developer.apple.com/ios/human-interface-guidelines/technologies/homekit/>. Acesso em: 24 ago. 2017 d.

APPLE. Siri - System Capabilities - iOS Human Interface Guidelines. Disponível em: <https://developer.apple.com/ios/human-interface-guidelines/system-capabilities/siri/>. Acesso em: 24 ago. 2017e.

APPLE. Voice (Siri) - Interaction - Human Interface Guidelines for CarPlay Apps. Disponível em: $<$ https://developer.apple.com/carplay/human-interface-guidelines/interaction/voice/>. Acesso em: 24 ago. $2017 f$. 
BARNUM, C. Usability Testing Essentials. 1. ed. Burlington, MA: Elsevier, 2011.

BLATTNER, M. M.; SUMIKAWA, D. A.; GREENBERG, R. M. Earcons and Icons: Their Structure and Common Design Principles. HUMAN-COMPUTER INTERACTION, v. 4, p. 11-44, 1989.

BUXTON, W.; GAVER, W.; BLY, S. Auditory Icons. In: AUDITORY INTERFACES: The Use of Non-Speech Audio at the Interface. [s.I: s.n.]. p. 1-17.

CLARK, J. Tapworthy: Designing Great iPhone Apps. 1. ed. Sebastopol, CA: O’Reilly, 2010.

GINSBURG, S. Designing the iPhone User Experience. 1. ed. Boston, Massachusetts: AddisonWesley, 2010.

GOOGLE. Consumer Barometer - $\quad$ Trending. Disponível em: $<$ https://www.consumerbarometer.com/en/trending/?countryCode=BR\&category=TRNNOFILTER-ALL>. Acesso em: 3 set. 2017a.

GOOGLE. Be Cooperative... Like Your Users. Disponível em: <https://developers.google.com/actions/design/be-cooperative>. Acesso em: 5 set. 2017b.

GOOGLE. In Conversation, There Are No Errors. Disponível em: <https://developers.google.com/actions/design/conversation-repair>. Acesso em: 5 set. 2017c.

GOOGLE. Instilling User Confidence Through Confirmations and Acknowledgements. Disponível em: <https://developers.google.com/actions/design/instilling-user-confidence>. Acesso em: 5 set. 2017d.

GOOGLE. Unlocking the Power of Spoken Language. Disponivel em: <https://developers.google.com/actions/design/unlocking-the-power-of-spoken-language>. Acesso em: 5 set. 2017e.

HOOBER, S.; BERKMAN, E. Designing Mobile Interfaces. 1. ed. Sebastopol, CA: O'Reilly, 2011. v. 2011

KORTUM, P. HCI Beyond the GUI. 1. ed. Burlington, MA: Elsevier, 2008.

ROGINSKA, A. Auditory Icons, earcons and displays: Information and expression through sound. In: TAN, S.-L. et al. (Eds.). . The Psychology of Music in Multimedia. [s.I.] Oxford University Press, 2013. p. 349-364.

SAFFER, D. Microinteractions: Designing with Details. 1. ed. Sebastopol, CA: O’Reilly, 2013.

SERAFIN, S. et al. Sonic Interaction Design. In: HERMANN, T.; HUNT, A.; NEUHOFF, J. (Eds.). . The Sonification Handbook. 1. ed. Berlin, Germany: Logos Publishing House, 2011. p. 88-110.

WALKER, B. N.; NEES, M. A. Theory of Sonification. In: HERMANN, T.; HUNT, A.; NEUHOFF, J. (Eds.). The Sonification Handbook. 1. ed. Berlin, Germany: Logos Publishing House, 2011. p. 9-39. 